\title{
Research on the impact of employee education composition on the business performance of e-commerce enterprises: based on the learning effect
}

\author{
Yaling Zhu \\ Administrative Engineering College, Zhengzhou University, No.100 science Avenue, Zhengzhou, \\ China \\ 1246615643@qq.com
}

Keywords: Learning effect; human capital; enterprise performance;

\begin{abstract}
With the arrival of knowledge economy, "talent" is playing an increasingly important role. The success of an enterprise, especially an e-commerce enterprise, largely depends on its ability and motivation of continuous innovation, which is mainly achieved by various talents in the enterprise. However, it has also become a problem for enterprises whether the highly educated talents will form the learning effect needed in social practice and business operation. The solution is to explore and prove the study on the impact of the academic structure of employees based on the learning effect on the business performance of e-commerce enterprises. At present, there is a lack of theoretical research on this aspect. Therefore, based on the perspective of learning effect, this paper attempts to open the study on the impact of employee education composition on the business performance of ecommerce enterprises, and puts forward some Suggestions for the management practice of enterprises.
\end{abstract}

\section{Introduction}

With the advent of the era of knowledge economy, human capital has gradually replaced traditional material resources as the source of maintaining sustainable competitive advantage and good financial performance due to its scarcity, unimitative and unsubstitutable characteristics. As one of the measuring standards of human capital quality, employee education is more and more concerned by enterprises and society.

In the 21st century, the characteristics of the era of knowledge economy have become increasingly prominent. As the bearer and creator of knowledge, highly educated talents have become the object of vigorous cultivation and competition by various countries and enterprises. The main feature of knowledge economy is that the leading factor of economic development is knowledge, which is essentially located in the carrier of knowledge, "human". Knowledge economy to a certain extent can be said to be the talent economy, than in the past the world called capitalist industrial economy era, knowledge economy is human capitalist economy era, the development of macroeconomic and microeconomic subject enterprise rise and fall of all depends on the talent attraction, retention, development, management and use. 
At present, China's e-commerce enterprises have become a large number of enterprise groups, and there are some large e-commerce enterprises with considerable strength. However, China's ecommerce enterprises started relatively late, and their development is unbalanced. Their contribution to economic and social development still lags behind that of developed countries or regions. Whether from the whole, or from the individual enterprise's comparison, the Chinese electronic commerce enterprise's innovation strength also appears very weak. And innovation depends more on human capital.

Human capital refers to the accumulation of knowledge and skills acquired by investment in education, training, practical experience, migration and health care, also known as "non-physical capital". According to the definition of human capital, the content of human capital is mainly the knowledge, skills, experience, health, etc. Knowledge, skills, experience, health and other resources are invisible and cannot be directly accessed from the outside world. These resources can only be learned and measured indirectly by means of education, training experience, years of employment, age, medical report, etc. Education is the most intuitive and the simplest criterion for judging. For the related research, first dates back to the Spence [3] (P35-74) (1973) pioneered the signal transmission theory, namely the ability of employers for applicants that depends largely on the degree, thus education is its ability to a display signal, this highly educated applicants employers recognized as having high learning ability. At present, the "research fever" in colleges and universities, the "evidence fever" among government officials, and the "consumption fever" of employers for higher education are still continuing to ferment. The pursuit of higher education can increase the human capital content of enterprises. However, in recent years, the negative news about "undergrads sweeping the floor", "graduate students selling goods" and even "doctoral students" is undoubtedly a major blow to enterprises and those with "high academic degrees". Whether highly educated talents have stronger learning ability and whether they can bring expected business benefits to e-commerce enterprises has been widely considered.

\section{Literature Review}

All kinds of management methods and measures in management mainly focus on how to improve enterprise performance and enhance enterprise competitiveness. The relationship between employee education composition and enterprise performance reflects the process of its influence on enterprise performance, that is, what is the intermediary between employee education composition and how to play a role in enterprise performance. Up to now, there is no clear and complete system, and in theory, there is no widely recognized and confirmed model to explain the mechanism of action between employee education composition and enterprise performance.

Through literature at home and abroad, and staff education form associated with the study of the relationship between the corporate performance of are: Asiaei and Jusoh skillfully using partial least squares (2015) on Tehran stock exchange 128 listed companies in the empirical analysis, found that the human capital investment and structural and relational have a significant role in promoting human capital on business performance; Wang zhuqing [6] (p101-03)(2002) used questionnaires to analyze the demand characteristics of individual enterprises for highly educated employees. The research believes that the enterprise's pursuit of survival and development is the main motivation for its need of highly educated talents, but it does not mention the impact of higher education on the enterprise. Zheng Jinghai etc. [7] (P521-540) (2002) state-owned enterprises efficiency and technical progress in the research, discovered the staff degree has significant effect for productivity growth, but the focus of this paper is to use data envelopment method and Malmquist index method, study the production performance of the enterprise, and without too much attention to education may have influence on firm's performance. As individual enterprises are an important base for 
attracting talents with higher education, it is of great significance to study the relevant role of education from the perspective of enterprises.

\section{Research Design}

The research object of this thesis is mainly the employees of zhengzhou e-commerce enterprises. Due to time, cost and other reasons, the questionnaire survey is mainly conducted in zhengzhou. Because the learning effect exists in the whole working process. In order to reduce the sampling error and avoid single sample, the author adopts the random sampling principle to select the survey object. In the pre-survey, A e-commerce enterprise and B e-commerce enterprise were selected as the objects of the survey, and employees were randomly selected in the enterprise for questionnaire issuance, and 100 copies were intended to be issued. In the formal survey, 200 questionnaires were issued.

On the basis of literature review, this paper constructs the theoretical model based on the research purpose of this paper and the previous research results of related researchers. This model mainly involves two variables: learning effect and job performance. The learning effect includes three dimensions: individual learning effect, organizational learning effect and over-learning effect. Work performance includes task performance and peripheral performance. In this paper, learning effect is defined as the independent variable of the study, work performance is defined as the dependent variable of the study, and the influence of different dimensions of learning effect on work performance and different dimensions is studied.

Previous empirical studies showed that employees showed different learning effects and job performance due to different factors such as gender, age, education and working years. Grass-roots managers have significant differences in work performance due to their different education, working years and job nature. Although the results of different researchers may vary somewhat, the influence of demographic factors on learning effect and job performance is unquestionable. This study believes that the learning effect and job performance of enterprise employees are significantly different due to their different demographic factors. For example, young employees newly employed may pay more attention to organizational learning effect than older employees. Because new young employees just entered the job, want to be integrated into the organization as soon as possible; On the other hand, older workers showed more outstanding performance in over-learning and higher work performance. The demographic factors in this study include gender, age, education, marital status, years of working and job position. Therefore, based on the above analysis, this paper proposes the following hypothesis.

Hypothesis 3: the learning effect of enterprise employees is significantly correlated with task performance.

Personal learning effect has significant negative effect on task performance.

The learning effect of the hierarchy has significant positive influence on task performance.

Excessive learning has a significant positive effect on task performance.

Hypothesis 4: there is a significant correlation between the learning effect of enterprise employees and peripheral performance.

Personal learning effect has significant negative effect on peripheral performance.

The learning effect of the hierarchy has significant positive influence on peripheral performance.

Excessive learning has a significant positive effect on peripheral performance.

Based on the theoretical research model of this paper and the above analysis, a research hypothesis is proposed. In the following sections, the author will verify the relevant research hypothesis through questionnaire survey and data analysis. 


\section{Research Steps}

The purpose of this study is to understand the effect of employee learning on enterprise performance and to provide references for enterprise managers on the structure of highly educated talents. Based on the purpose of this study, the steps of this study are mainly divided into the following stages:

Step 1: based on the analysis of relevant research status at home and abroad and relevant theories, the research object of this paper is determined, and the research model and hypothesis of this paper are proposed.

Step 2: on the basis of literature review, the questionnaire items of this paper are summarized and sorted out by referring to the mature scales that are recognized and tested at home and abroad.

Step 3: take employees of A and B e-commerce enterprises in zhengzhou as samples to issue questionnaires.

Step 4: collect valid questionnaires, sort out the data of effective questionnaires and input them to the computer. Then use statistical software to make statistical analysis of the obtained data and test the research hypothesis.

Step 5: summarize the research results and make relevant discussions, put forward relevant Suggestions, summarize the deficiencies of this study and the future research prospects.

\subsection{The Questionnaire Design}

The questionnaire of this study consists of three parts: the first part is the basic personal situation; the second part is the learning effect job scale; the third part is the work performance scale.

(1) Basic personal information

The personal basic situation scale contains the items, namely, gender; (2) age; Marital status; (4) education; Length of service; An entry-level job.

(2) Work scale of learning effect

The work scale of learning effect used in this paper includes three aspects: individual learning effect, organizational learning effect and expression of over-learning effect.

(3) Work performance scale

The classic two-dimensional model of work performance proposed by Borman and Mototwidlo in 1993 is a performance model with high recognition and wide application at present. In this study, the classic two-dimensional model of Borman and Mototwidlo is adopted to divide work performance into task performance and peripheral performance. The design of work performance scale in this paper is also based on the reference and related research of Borman and Mototwidlo. The work performance scale consists of two dimensions, 12 items, task performance 6 (1-6) and peripheral performance 6 (7-12). All items in the learning effect work scale were scored by 5 points, from 1 to 5 , representing complete nonconformity to complete conformity. The higher the score, the higher the performance of the subjects.

\subsection{The Questionnaire Survey}

The sample survey was conducted in zhengzhou, henan province. The respondents selected were employees of An e-commerce enterprise and B e-commerce enterprise, which lasted for 10 days. A total of 60 questionnaires were issued and 60 were recovered. After the questionnaire was recovered, the incomplete information, missing answers, and the subjects did not fill in the questionnaires carefully were eliminated. After the elimination, 53 effective questionnaires were recovered and the recovery rate of effective questionnaires was $88 \%$. 


\section{Research results and implications}

This study through to the zhengzhou area employees learning effects on enterprise performance study found that the influence of enterprise employees work in the process of learning effect is an important part of enterprise staff job ability promotion, learning effect has a significant effect on corporate performance, but the current enterprise managers lack of attention to emotional work, less attention to from the perspective of human resource development and management. Therefore, based on the research conclusion of this paper, the author puts forward the following Suggestions for the emotional work management of enterprise employees from the perspective of human resource management:

The increasingly serious phenomenon of brain drain requires the human resource department of an enterprise to do a good job of human resource planning and prediction, and reserve the corresponding talents for the enterprise in advance, and the learning effect of employees is one of the key factors influencing the work performance and service quality. Therefore, the employee learning effect plan should be incorporated into the schedule of human resource planning. Meanwhile, the employee learning effect development plan should be made, and the supply and demand prediction of employees should be made well.

\section{References}

[1] Juan, Wang, Yi Wang, 2016. Educational level of enterprise employees and enterprise innovation performance, Journal of xi 'an jiaotong university.(6).

[2] Weiqing, Hua, Yan,. Luo, 2015. Innovative educational background executives and corporate performance empirical study, Journal of jiangxi normal university. (03).

[3] Chunli, Wang, Gianan Cao.2007.Research on the correlation between the size, performance and technical personnel of listed companies. Research on technology management.(6):pp55-62.

[4] Zhan Cao, 2017.Research on collaborative evaluation model construction of cross border electricity supplier and logistics -- Based on the synergy degree model of composite system, Chinese Business Theory, (22) pp.52-54.

[5] Erzi Tang,zhen sun,2010.staff degree, corporate performance, and per capita salary, Social sciences in Beijing. (05).

[6] Xinchen Wang, 2016. The application of web data mining in enterprise database marketing and customer relationship management, Information and Computer (theoretical), 4(22): 155-156.

[7] Lan Xiong, Bing Gao, 2017. Study on customer segmentation based on RFM multi-level customer value model, Commercial Economics Research, (05): 55-57.

[8] Yujue wang.2012.technical staff input and the growth of small and medium-sized listed companies, theory (16).

[9] Lixia Feng,qi.an zhang.2007. Empirical analysis of the relationship of human capital and enterprise performance, accounting communication. (02).

\section{Appendix}

Dear madam and Sir:

The questionnaire

Hello! Thank you for your help in completing this questionnaire survey. This questionnaire is divided into three parts

It takes about 5 minutes to complete the whole questionnaire. This questionnaire is intended to study the influence of the employee learning effect on job performance, no right or wrong answers to all questions, you can choose the answer only for academic research, the questionnaire to fill in using anonymous way, your any information will be strictly confidential, please truthfully answer according to their real idea, you really think the accuracy of this research is very important! Thank you very much for your support to this study. I wish you good health and smooth work!

Part one: personal data

Answer: please change the number to red according to your actual situation. 


\section{Your gender}

2. Your age: u 22 and below; 22-35 years old; 35-50 years old; over 50 years old

Marital status: unmarried unmarried married

4. Education: bachelor degree or above in junior high school or higher

5 . Working years: less than 5 years and less than 5-10 years and more than $10-20$ years

6. Job position: subordinate to general staff and subordinate to senior management

Part two: the study effect questionnaire

Answer: this part is mainly about how you learn management in your work. Please change the number of the corresponding options to red according to your own experience. The number represents the degree to which the sentence is consistent with you, as follows: $1=$ completely inconsistent; $2=$ partial nonconformity; $3=$ uncertainty; $4=$ partial compliance; $5=$ exactly.

1 the work process is dominated by individual learning 1, 2, 3, 4 and 5

2 the work process is dominated by organizational learning 1, 2, 3, 4 and 5

3. In the working process, I mainly focus on personal learning, with organizational learning as the auxiliary 1, 2, 3, 4 and 5

4 in the working process, organizational learning is the main and personal learning is the auxiliary 1, 2, 3, 4 and 5

5. In the working process, I think I conform to over-learning effect 1, 2, 3, 4 and 5

The third part

Answer: this part is mainly about how you learn management in your work. Please change the number of the corresponding options to red according to your own experience. The number represents the degree to which the sentence is consistent with you, as follows: $1=$ completely inconsistent; 2 = partial nonconformity; $3=$ uncertainty; $4=$ partial compliance; $5=$ exactly.

Conform to the degree of

Qid topic

1 my quality of work remains high and I rarely make mistakes 1, 2, 3, 4, 5

2 the effect of my work has been recognized by everyone 1, 2, 3, 4, 5

3 I often plan and arrange the schedule of the work I am responsible for 1, 2, 3, 4 and 5

4 I can always finish my work accurately and efficiently1, 2, 3, 4, 5

5 I always finish tasks within the given time1, 2, 3, 4, 5

6. The work tasks I completed conform to my expectations and the requirements of my superiors1, 2, 3, 4, 5

7 I would very much like to stay in this department1, 2, 3, 4, 5

8 I am very willing to do my best to do the work well1, 2, 3, 4, 5

9 I often take the initiative to take on jobs other than my own1, 2, 3, 4, 5

10 I often take the initiative to help others in my unit to finish their work1, 2, 3, 4, 5

11 I often communicate with colleagues actively and get on well with them 1, 2, 3, 4 and 5

12 I take the initiative to pay attention to the situation of the company and offer Suggestions for the development of the company1, 2, 3, 4, 5 